\title{
ŠTUDENTJE, ŠKRATJE IN NADŠKOFJE: KONČNICA -JE V IMENOVALNIKU MNOŽINE PRI SAMOSTALNIKIH PRVE MOŠKE SKLANJATVE
}

\section{Špela ARHAR HOLDT}

Trojina, zavod za uporabno slovenistiko

Arhar Holdt, Š. (2013): Študentje, škratje in nadškofje. Končnica -je v imenovalniku množine pri samostalnikih prve moške sklanjatve. Slovenščina 2.o, 1 (1): 134-154.

URL: http://www.trojina.org/slovenscina2.o/arhiv/2013/1/Slo2.o_2013_1_o7.pdf.

Ena izmed oblikoslovnih posebnosti slovenskega jezika je možnost rabe končnice -je namesto $-i \mathrm{v}$ imenovalniku množine pri določenih samostalnikih prve moške sklanjatve (npr. študenti - študentje). Prispevek predstavlja rezultate korpusne analize, ki kaže, kateri slovenski samostalniki se v sodobni slovenščini pojavljajo s končnico -je in kako jih je mogoče nadalje kategorizirati ter na osnovi tega sklepati o tendencah posamezne od variant v rabi. Prispevek umešča nove ugotovitve ob informacije, ki jih o tej temi lahko iz obstoječih referenčnih priročnikov dobi zainteresirani jezikovni uporabnik.

Ključne besede: oblikoslovne variante, samostalnik, prva moška sklanjatev, končnica -je

\section{PREDSTAViteV PROBLEMA}

Ena izmed oblikoslovnih posebnosti slovenskega jezika je možnost uporabe končnice -je namesto - $i \mathrm{v}$ imenovalniku množine pri določenih samostalnikih prve moške sklanjatve (npr. študenti - študentje, škrati - škratje, škofi škofje).

\subsection{Opis variatnosti $-i /$-je v referenčnih jezikovnih priročnikih}

V Slovenski slovnici (Toporišič 2004: 283) lahko preberemo naslednje:

Nekaj samostalnikov ima v im. mn. poleg končnice $-i$ še končnico -je: kmet kmeti in kmetje, dalje navadno, tj. kmet-ov -om itd. Bolj običajna kot -i je 
končnica -je npr. pri naslednjih samostalnikih: bratje (stil. brati), dedje (in dedi), fantje (stil. fanti), gospodje (stil. gospódi), gostje (tudi gôsti), očetje (tudi očeti). Gre tudi še golobje (poleg golobi), sosedje (in sosedi), škratje (poleg škrati), grofje (poleg grofi), ne pa več Gotje, grobje, snopje ali celo Ljubljančanje ali Celjanje. Oboje je že stilno zaznamovano.

Slovnica bralcu torej podaja naslednje okvirne informacije: (I) opisana variantnost se pojavlja le pri nekaterih samostalnikih, (II) v določenih od teh primerov je bolj običajna končnica -je, v drugih končnica -i, (III) končnica -je se je $\mathrm{v}$ preteklosti uporabljala tudi pri primerih, kjer je danes stilno zaznamovana.

Slovnica podaja splošno predstavitev oblikoslovne posebnosti s pomočjo nekaterih izbranih primerov, informacijo o variantnosti pri posameznem, določenem samostalniku pa je mogoče dobiti v Slovarju slovenskega knjižnega jezika (SSKJ) oziroma v Slovenskem pravopisu (SP). ${ }^{1}$ Tudi del pravopisa, ki prinaša pravila, neposredno preusmeri bralca na slovarski del: »Pri samostalnikih, ki imajo posebne končnice, so te zapisane v slovarju: kmèt kmétje, zób - zobjé.« (Pravila SP 2001: § 797.)

Tako kot v navedku iz Slovenske slovnice je razmerje med obema variantnima možnostma v slovarjih opredeljeno s kvalifikatorji tudi, in ter stil. oziroma redk. Vsi trije priročniki torej predpostavljajo, da bo uporabnik razumel razlike, ki jih glede rabe nakazujejo posamezni kvalifikatorji (o tem gl. Uvod v SSKJ: § 117-119). Vprašanj, pri katerih samostalnikih SSKJ in SP beležita variantnost in katerih ne, kako je $\mathrm{v}$ slovarjih opredeljeno razmerje med variantami in na kakšen način si s podatki lahko pomagajo jezikovni uporabniki, se dotikamo v nadaljevanju prispevka.

\footnotetext{
${ }^{1} \mathrm{~V}$ raziskavi sta bila uporabljeni različici, ki sta prosto dostopni na spletu: http://bos.zrcsazu.si/sskj.html in http://bos.zrc-sazu.si/sp2001.html.
} 
$\mathrm{V}$ prispevku se osredotočamo predvsem na podatke $\mathrm{v}$ referenčnih jezikovnih priročnikih, kamor štejemo Slovensko slovnico (Toporišič 2004 in predhodni izidi), slovar SSKJ in SP. Podatke o obravnavani variantnosti je sicer mogoče dobiti tudi $\mathrm{v}$ nekaterih novejših spletnih virih, kot sta denimo leksikon besednih oblik Sloleks ${ }^{2}$ in pregibnik Amebis Besana. ${ }^{3}$

\subsection{Vzroki za variantnost $-i$-je}

$\mathrm{V}$ prispevku pristopamo $\mathrm{k}$ vprašanju variantnosti - $i$-je s sinhronega vidika, zato se vzroka za njen nastanek na tem mestu dotikamo le na hitro.

Analize gradiva slovenskih protestantskih piscev 16. stoletja so pokazale visoko stopnjo oblikoslovne variantnosti, med drugim je bila identificirana tudi varianta, ki jo obravnavamo $\mathrm{v}$ tem prispevku (raziskave pregledno povzema Merše 2009). Variantnost je posledica več prepletenih dejavnikov, predvsem dejstva, da so v začetni fazi knjižnega jezika pisci sklanjatvene in spregatvene oblike glede na nove zahteve ubeseditev šele »aktivirali«, odkrivali, pri čemer so se opirali na različne vire (Orožen 1994). 4 Čeprav je šla kasnejša standardizacija v smer redukcije variant, se je začetna neustaljenost $\mathrm{v}$ jeziku v določeni meri obdržala. To je moč opaziti tudi pri varianti $-i /-j e: \mathrm{v}$ splošnem smislu je v zgodovinskem razvoju prevladala končnica $-i$, končnica -je pa je ostala pogosteje ali redkeje rabljena varianta le pri določenih samostalnikih.

\footnotetext{
2 http://www.slovenscina.eu/sloleks/

3 http://besana.amebis.si/pregibanje/

4 »V nasprotju /so si/ oblike narečnega prostora v smeri jugovzhod-severozahod, na drugi strani pa sočasnim govornim oblikam v omejenem obsegu še konkurirajo starinske, govorno že nepotrjene oblike, značilne predvsem za Trubarjev jezik. Gre za prepletanje sestavsko različnih govornih oblikoslovnih prvin, ki so tudi stilsko izkoriščane.« (Orožen 1994: 326327.)
} 


\subsection{Variantnost - i/-je kot jezikovna zadrega}

Variantnost $-i$ /-je jezikovnim uporabnikom včasih povzroča težave, najbrž ravno zato, ker je s sinhronega vidika ni lahko sistematično in premočrtno razložiti. V Tabeli 1 je eno izmed vprašanj, ki je bilo pred nekaj leti zastavljeno na portalu Med.Over.Net, in odgovor nanj. 5

\begin{tabular}{|c|c|}
\hline Tema & Študenti / študentje? \\
\hline Vprašanje & $\begin{array}{l}\text { Prosim za razlago. } \\
\text { Kakšna je razlika med študenti/študentje ter podobnimi besedami? Npr. } \\
\text { sosedi/sosedje ... } \\
\text { Najlepša hvala. }\end{array}$ \\
\hline Odgovor & $\begin{array}{l}\text { V resnici pomenske razlike ni. Tudi pravopis enakovredno dovoljuje obe } \\
\text { možnosti. } \\
\text { Osebno čutim rahlo razliko (prej stilno kot vsebinsko) v tem, da bi -je } \\
\text { uporabila, ko mislim splošno skupino ( ̌̌tudentje so priredili množične } \\
\text { demonstracije.), -i pa, ko imam v mislih neke (konkretne) posameznike } \\
\text { (Študenti, ki sem jih spoznala v Mariboru, so bili zelo prijazni.). } \\
\text { Prav tako bi uporabila -i, če bi pred tako besedo stal števnik trije (trije } \\
\text { študenti, trïe kmeti). } \\
\text { Paziti je treba, da nas tale -je ne zanese tudi tam, kjer ga ni (npr. } \\
\text { agentje). }\end{array}$ \\
\hline
\end{tabular}

Tabela 1: Primer vprašanja in odgovora s portala Med.Over.Net.

Primer je bil izbran, ker dobro predstavlja glavno vprašanje, ki ga imajo jezikovni uporabniki v zvezi z obravnavano variantnostjo: kakšna je razlika

5 Raziskava, s katerimi jezikovnimi težavami se uporabniki slovenščine najpogosteje srečujejo (Dobrovoljc, Krek 2011), je pokazala, da uporabniki pomoč pri reševanju jezikovnih zadreg pogosto iščejo (tudi) po različnih spletnih forumih. Eno takšnih spletnih mest je forum $A l^{\prime}$ prav se piše ... portala Med.Over.Net (http://med.over.net/forum5/list.php?125). Za več o tem forumu in forumskem svetovanju gl. denimo Hribar 2009; Žaucer, Marušič 2009. 
med oblikama oz. katero od oblik uporabiti (katera je ustreznejša/pravilnejša).

Precej o razumevanju problema izvemo tudi ob branju forumskih odgovorov. V predstavljenem odgovoru poskuša avtorica na osnovi jezikovnega občutka podati nekaj smernic glede rabe ene in druge oblike. S stališča uporabe jezikovnih priročnikov je zanimivo tudi opozorilo na koncu odgovora, ki svari pred rabo oblike agentje, ker ni zajeta v pravopisni slovar. ${ }^{6}$

\subsection{Namen prispevka}

Pričujoči prispevek k opredeljeni tematiki pristopa s korpusnojezikoslovnega vidika. Prvi namen raziskave je identificirati, kateri samostalniki v korpusu

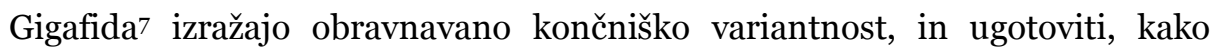
pogosta je varianta -je pri posameznem od teh samostalnikov. Drugi namen raziskave je ugotoviti, ali dobljeni rezultati nakazujejo značilnosti ali tendence, na osnovi katerih bi bilo mogoče obstoječi jezikovni opis razširiti oz. dopolniti - predvsem z informacijami, ki bi lahko bile $\mathrm{v}$ pomoč pri reševanju jezikovnouporabniških zadreg.

\section{METODA}

Raziskava združuje kvalitativno in kvantitativno korpusnojezikoslovno analizo.

\footnotetext{
${ }^{6} \mathrm{~K}$ vprašanju rabe oblike agentje se vračamo v poglavju 4, kot zanimivost pa lahko na tem mestu napišemo, da analiza podatkov v korpusu Gigafida ne potrdi smernic za razlikovanje med oblikama na osnovi tega, ali gre za splošno skupino ali znane posameznike. Pri rabi zvez s števnikom trije se izkažejo celo ravno nasprotne tendence: trije študentje: 104 pojavitve, trïe študenti: 37 pojavitev; trïe kmetje: 39 pojavitev, trïe kmeti: 2 pojavitvi.

7 Korpus je dostopen na strani http://www.gigafida.net. O korpusu Logar Berginc in dr. 2012.
} 


\subsection{Luščenje korpusnih podatkov in prva selekcija}

V prvem koraku so bile iz korpusa Gigafida avtomatsko pridobljene vse besede, ki se končajo tako na - $i$ kot na -je, skupaj s podatkom o pogostnosti in oblikoskladenjski označenosti teh oblik. Prvotne rezultate - kar 16.973 takšnih parov - smo nadalje avtomatsko selekcionirali z izločitvijo vseh parov, pri katerih vsaj ena od oblik ni bila označena kot samostalnik moškega spola. $\mathrm{Na}$ tak način je odpadla velika večina nerelevantnih rezultatov (npr. abstrakciji - abstrakcije; abstrahirani - abstrahiranje). ${ }^{8} \mathrm{~V}$ drugem koraku so bili iz nadaljnje obravnave izločeni primeri, pri katerih se pred končnico pojavlja črka j (abonmaji - abonmaje) ali črka r (okviri - okvirje). 9

\subsection{Ročna selekcija rezultatov}

Po prvih selekcijah je na seznamu ostalo 1629 parov samostalnikov, ki so bili nadalje ročno selekcionirani $\mathrm{s}$ pomočjo pregleda konkordančnih nizov $\mathrm{v}$ korpusu Gigafida. Med selekcijo so bili izločeni primeri, pri katerih se v paru s samostalnikom moškega spola pojavlja samostalnik srednjega spola (grmiči grmičje), pridevnik (ptiči - ptičje) ipd. Odstranjeni so bili tudi primeri, ki so vsebovali tipkarske napake (npr. studenti - studentje), prav tako so bili iz nadaljnje obravnave odstranjeni primeri dejanskih oblikovnih variant, če se je vsaj ena od njiju pojavljala le v navedkih iz arhaičnih besedil. ${ }^{10}$ Po koncu selekcije je ostalo na seznamu 176 samostalnikov.

\footnotetext{
${ }^{8}$ Seveda bi bilo mogoče že takoj na začetku določiti, da se izluščijo samo primeri, pri katerih je vsaj ena od oblik samostalniška, druga pa bodisi samostalniška bodisi nelematizirana, kar bi prihranilo nekaj časa, vendar pa bi obenem izgubili pregled nad tem, kaj v analizo ni bilo zajeto.

9 Pri samostalnikih moškega spola na $-r$ sicer tudi gre za oblikoslovno varianto, ampak druge vrste (podaljševanje osnove $\mathrm{z}-j$-).

${ }^{10}$ Primer takšne rabe: Komisar Lanjšič, ki je prevzel upravo v Prekmurju, je izdal razglas, kjer je zapisal: "Vi ste ne več Vogri, nego Jugoslovani, sinovje domovine, po rodu Slovenci!" (Dnevnik, 1999.)
} 


\subsection{Kategorizacija samostalnikov}

Ker izvorni podatek o pogostnosti oblik na -i vključuje tudi orodniške oblike ( $s$ študenti), se v raziskavi opiramo na podatke o tem, v koliko primerih je oblika označena kot samostalnik moškega spola v imenovalniku množine.

Oblikoskladenjsko označevanje slovenščine sicer ni 100-odstotno zanesljivo, enako velja za razdvoumljanje enakopisnih oblik, s čimer se pri obravnavanem problemu pogosto srečamo. ${ }^{11}$ Zato smo samostalnike razvrstili v nekoliko ohlapnejše kategorije, in sicer $\mathrm{v}$ devet skupin glede na to, kolikšen delež predstavlja v podatkih varianta na -je. Pri uvrščanju v skupine je bil podatek o pogostnosti oblike preverjen s hitrim pregledom konkordanc za vsako od obravnavanih oblik posebej. Rezultate predstavlja poglavje 3.1.

Samostalniki so bili nato natančneje analizirani z oblikovnega in pomenskega vidika z željo odkriti morebitne združujoče značilnosti, ki bi pomagale variantnost $-i /$-je bolje razumeti. Relevantne tendence so se pokazale pri razvrstitvi samostalnikov glede na podspol človeškosti oz. živosti in glede na to, kako se konča osnovna oblika samostalnika. Rezultate predstavljata poglavji 3.2 in 3.3 .

3 REZULTATI ANALIZE

\subsection{Razvrstitev samostalnikov glede na pogostnost variante -je}

Glede na podatek o tem, kako pogosto se v korpusu Gigafida določen samostalnik pojavlja $\mathrm{z}$ varianto -je, smo 176 samostalnikov razvrstili $\mathrm{v}$ devet skupin, ki jih prikazuje Tabela 2. Tabela prinaša zaporedno številko

\footnotetext{
${ }_{11}$ Tipičen primer je denimo oblika dedi, ki je pogosto napačno označena kot imenovalnik množine besede ded, čeprav gre za v resnici za ljubkovalnico besede dedek v imenovalniku ednine.
} 
posamezne skupine, opredelitev skupine glede na delež pojavljanja variante -je, število primerov, ki jih skupina prinaša, in $\mathrm{v}$ zadnjem stolpcu vse ustrezajoče samostalnike, urejene abecedno.

\begin{tabular}{|c|c|c|c|}
\hline Skupina & $\begin{array}{c}\text { Delež } \\
\text { pojavitev } \\
\text { variante -je }\end{array}$ & $\begin{array}{l}\text { Št. } \\
\text { primerov }\end{array}$ & Samostalniki \\
\hline 1 & skoraj vedno & 4 & človek, las, mož, zob'12 \\
\hline 2 & 95 do $99 \%$ & 8 & $\begin{array}{l}\text { brat, fant, gospod, gost, kmet, oče, } \\
\text { slačifant, sobrat }\end{array}$ \\
\hline 3 & 85 do $95 \%$ & 4 & nekmet, polbrat, polkmet, praoče \\
\hline 4 & 65 do $85 \%$ & 7 & $\underset{\text { žid, }}{\text { grof, jud, pob, praded, sosed, škof, }}$ \\
\hline 5 & 35 do $65 \%$ & 10 & $\begin{array}{l}\text { ded, maturant, muzikant, nejud, } \\
\text { nadškof, prapraded, škrat, špekulant, } \\
\text { študent, žirant }\end{array}$ \\
\hline 6 & 15 do $35 \%$ & 9 & $\begin{array}{l}\text { agent, ajd, bastard, cirkusant, } \\
\text { manifestant, nežid, soldat, svat, ud }\end{array}$ \\
\hline 7 & 5 do $15 \%$ & 24 & $\begin{array}{l}\text { dekadent, diletant, falot, freskant, gad, } \\
\text { Hrvat, ignorant, inkasant, intendant, } \\
\text { intrigant, kolaborant, lump, magistrat, } \\
\text { medved, opat, Osilničan, penat, pezde, } \\
\text { politikant, praktikant, protestant, } \\
\text { respondent, trafikant, zabušant }\end{array}$ \\
\hline 8 & 1 do $5 \%$ & 44 & $\begin{array}{l}\text { abonent, absolvent, adolescent, } \\
\text { asistent, azilant, birt, demonstrant, } \\
\text { diplomant, disident, docent, debitant, } \\
\text { emigrant, gigant, golob, Got, imigrant, } \\
\text { jezuit, jubilant, kamerad, knap, } \\
\text { komedijant, konkurent, kooperant, }\end{array}$ \\
\hline
\end{tabular}

${ }^{12}$ Za to skupino samostalnikov je značilno, da je končnica -je glede na jezikovna pravila v standardni slovenščini edina ustrezna; gre tudi za edino skupino, pri kateri je končnica naglašena (lasjé, ljudjé, možjé in zobjé).

13 Pri jud, žid, nejud in nežid smo primere, zapisane z veliko in malo začetnico združili, zato je v tabelah naveden samo zapis z malo začetnico. 


\begin{tabular}{|c|c|c|c|}
\hline & & & $\begin{array}{l}\text { koproducent, labod, laborant, Ložan, } \\
\text { migrant, manipulant, ministrant, } \\
\text { mutant, poet, pop, prevarant, } \\
\text { projektant, pust, recenzent, referent, } \\
\text { reprezentant, Ribničan, sonet, } \\
\text { specializant, Škot, zet }\end{array}$ \\
\hline 9 & $\begin{array}{l}\text { sporadično } \\
\text { (manj kot v } 1 \% \\
\text { primerov oz. le s } \\
\text { posameznimi } \\
\text { pojavitvami) }\end{array}$ & 66 & $\begin{array}{l}\text { akrobat, aristokrat, bandit, Berce, bob, } \\
\text { cigan, dedec, demokrat, dirigent, } \\
\text { diplomat, diverzant, Dobčan, filozof, } \\
\text { fizioterapevt, furman, glas, goljuf, } \\
\text { idiot, interesent, kadet, kandidat, } \\
\text { katehet, knez, knezoškof, komitent, } \\
\text { koncertant, kurent, literat, } \\
\text { Ljubljančan, meščan, obroč, pacient, } \\
\text { pedant, pilot, pirat, Podgožan, pogan, } \\
\text { predikant, pretendent, producent, } \\
\text { profet, rezident, robot, Rus, } \\
\text { sekundant, seržant, skavt, Slovenec, } \\
\text { Socialdemokrat, sogost, sovrag, Srb, } \\
\text { Šegovščan, Šved, tat, tehnokrat, } \\
\text { terorist, turist, usrane, vagant, } \\
\text { Višnjan, voz, zafrkant, zaspane, } \\
\text { zmikavt, Žužemberčan }\end{array}$ \\
\hline
\end{tabular}

Tabela 2: Razvrstitev samostalnikov glede na pogostnost končnice -je.

Med sliko, ki jo prikazuje korpus Gigafida, in sliko, ki jo podajajo jezikovni priročniki, je najti kar nekaj razlik. Do določene mere pričakovana oz. razumljiva razlika je, da SSKJ in SP variantnost beležita le pri tistih primerih, ki so v Tabeli 2 uvrščeni v skupine od 2 do 6 (pri večini, ne pa vseh). ${ }^{14}$ Primeri iz skupin 7 do 9 so kot varianta navedeni zelo redko. ${ }^{15}$

Razlike je najti tudi na ravni opredeljevanja razmerja med oblikama. Za primer $\mathrm{v}$ Tabeli 3 navajamo samostalnike, pri katerih se $\mathrm{v}$ imenovalniku

\footnotetext{
${ }_{14}$ Manjka pri geslih agent, bastard, cirkusant, manifestant, soldat, žirant. Samostalnika nežid in nejud v slovarja nista zajeta, prav tako v SSKJ-ju še ni najti besede slačifant. $15 \mathrm{~V}$ SP recimo pri geslih falot, gad, golob, knezoškof, labod, lump, medved, ministrant, protestant, sonet, tat in zet.
} 
množine varianta -je pojavi med 95 in 99 odstotki, skupaj s podatkom, kako je razmerje med variantama opredeljeno v SSKJ, SP in Slovenski slovnici.

\begin{tabular}{|c|c|c|c|c|}
\hline Primer & Korpus Gigafida & SSKJ & SP & $\begin{array}{l}\text { Slovenska } \\
\text { slovnica }\end{array}$ \\
\hline brat & bratje $v$ pribl. $99 \%$ & $\begin{array}{l}\text { bratje stil. } \\
\text { brati }\end{array}$ & $\begin{array}{l}\text { bratje tudi } \\
\text { brati }\end{array}$ & $\begin{array}{l}\text { bratje stil. } \\
\text { brati }\end{array}$ \\
\hline fant & fantje v pribl. $99 \%$ & fantje stil.fanti & $\begin{array}{l}\text { fantje tudi } \\
\text { fanti }\end{array}$ & fantje stil. fanti \\
\hline slačifant & $\begin{array}{l}\text { slačifantje v pribl. } \\
98 \%\end{array}$ & / & $\begin{array}{l}\text { slačifantje tudi } \\
\text { slačifanti }\end{array}$ & / \\
\hline oče & očetje v pribl. $98 \%$ & očetje tudi očeti & očetje tudi očeti & očetje tudi očeti \\
\hline kmet & kmetje v pribl. $98 \%$ & $\begin{array}{l}\text { kmetje stil. } \\
\text { kmeti }\end{array}$ & $\begin{array}{l}\text { kmetje redk. } \\
\text { kmeti }\end{array}$ & kmeti in kmetje \\
\hline gospod & $\begin{array}{l}\text { gospodje v pribl. } \\
97 \%\end{array}$ & $\begin{array}{l}\text { gospodje stil. } \\
\text { gospodi }\end{array}$ & $\begin{array}{l}\text { gospodje tudi } \\
\text { gospodi }\end{array}$ & $\begin{array}{l}\text { gospodje stil. } \\
\text { gospodi }\end{array}$ \\
\hline sobrat & $\begin{array}{l}\text { sobratje v pribl. } \\
95 \%\end{array}$ & $\begin{array}{l}\text { sobratje tudi } \\
\text { sobrati }\end{array}$ & $\begin{array}{l}\text { sobratje tudi } \\
\text { sobrati }\end{array}$ & / \\
\hline gost & gostje v pribl. $95 \%$ & $\begin{array}{l}\text { gostje tudi } \\
\text { gosti }\end{array}$ & $\begin{array}{l}\text { gostje tudi } \\
\text { gosti }\end{array}$ & $\begin{array}{l}\text { gostje tudi } \\
\text { gosti }\end{array}$ \\
\hline
\end{tabular}

Tabela 3: Primerjava opredelitve razmerja med variantami v različnih jezikovnih virih.

Največjo razliko glede na korpusne podatke (in tudi glede na ostala dva priročnika) predstavlja temno sivo označena celica v Tabeli 3. S svetlo sivo pa so označeni primeri, pri katerih je razmerje med variantama označeno $\mathrm{s}$ kvalifikatorjem tudi in ne z redko (oz. stilno), kar bi najbrž izbrali, če bi samostalnike kvalificirali glede na predstavljene korpusne podatke. Ta informacija je toliko bolj pomembna, če vemo, da se tudi pri drugih samostalnikih iz skupin 2 do 6 pogosto izkazuje, da SSKJ in SP varianti s 
končnico -i pripisujeta nekoliko višjo "pomembnost «, kot bi jo ta dobila na podlagi korpusnih podatkov. Za SP je to bolj značilno kot za SSKJ, kar morda nakazuje zavestno težnjo jezikovne norme $\mathrm{v}$ smer redukcije obravnavane jezikovne variante.

\subsection{Razvrstitev samostalnikov glede na podspol človeškosti}

Če na identificirane samostalnike pogledamo v luči podspolov človeškosti in živosti, je mogoče opaziti prepričljive tendence pojavljanja končnice -je. Kar 93 \% vseh samostalnikov namreč poimenuje človeško, denimo človeka določene starosti (fant, mož, adolescent), sorodstvenega razmerja (oče, brat, ded), poklica (inkasant, pilot, dirigent), naziva (docent, absolvent, asistent), družbenega stanu (grof, škof, kmet), funkcije (žirant, reprezentant, kandidat), narodnosti (Hrvat, Škot, Šved) itd. V posebno skupino smo uvrstili samostalnike ajd, gigant, mutant, robot in škrat, ki načeloma poimenujejo človeku podobno bitje, vendar nekateri samo v določenih kontekstih. Ta skupina s slovničnega vidika seveda ne predstavlja lastne kategorije, $\mathrm{z}$ vidika raziskave pa je kljub temu na meji med prvo in drugo skupino, zato je na Sliki 1 prikazana ločeno.

Samostalnikov, ki poimenujejo nečloveško, je v analiziranih podatkih le 12 (7\%): dva primera sta iz prve skupine Tabele 2 in $\mathrm{v}$ tem smislu izjemi (las, zob), štirje primeri se v korpusu pojavljajo le po enkrat (bob, glas, obroč, voz), beseda sonetje pa je močno vezana na naslov Sonetje nesreče in jo imamo v tem smislu lahko za arhaično. Ostanejo štiri poimenovanja živali (gad, golob, labod, medved), od katerih v sodobnem jeziku najdemo predvsem obliko medvedje, druge so redkejše. ${ }^{16}$ Nenazadnje je v skupini še samostalnik $u d$.

16 Obliki golobje in labodje na ravni pogostnosti precej pridobita na račun (starejših) stvarnih imen Golobje, sidro in vodnjak in Trije labodje. Tudi oblika gadje je v določeni meri vezana na stvarna imena (To so gadje, Dolski gadje, Gadje iz Šiške ipd.), vendar je v rabi vseeno nekoliko pogostejša. 
Končnica -je $\mathrm{v}$ imenovalniku množine se pri tem samostalniku pojavlja relativno pogosto in razpršeno po besedilnih virih, kljub temu da gre za v slovničnem smislu poimenovanje nečloveškega oz. neživega (ohromeli udje).

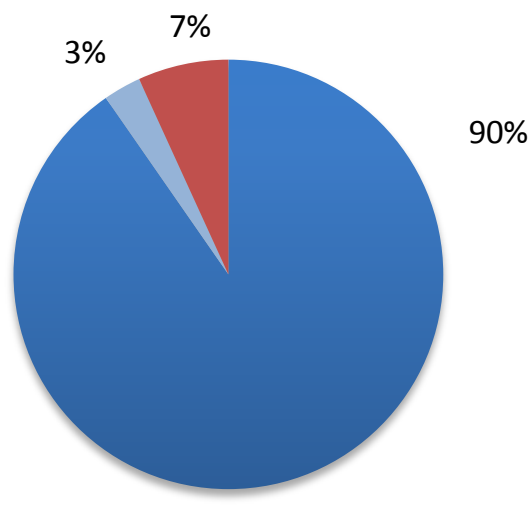

človeško

- (človeku podobno)

nečloveško

Slika 1: Delež samostalnikov glede na podspol človeškosti.

\subsection{Razvrstitev samostalnikov glede na zadnjo črko osnove}

Slika 2 prikazuje, na katero črko ${ }^{17}$ se končajo osnove analiziranih samostalnikov v imenovalniku množine. Modri stolpci predstavljajo celotno število samostalnikov, pri rdečih pa so odšteti primeri, pri katerih se končnica -je pojavi le sporadično (skupina $9 \mathrm{v}$ Tabeli 2 ). ${ }^{18}$ Kot kažejo podatki, je pojav končnice -je posebej pogost pri osnovah na $-t$, nekoliko manj pri osnovah na $-d, \mathrm{v}$ preostalih primerih pa je končnica -je redka oz. se sploh ne pojavi.

\footnotetext{
17 Ker analiza poteka na podatkih iz pisnega korpusa, se osredotočamo na pisno podobo besed in posledično govorimo o črkah, ne pa (tudi) o glasovih. V nadaljevanju bi bilo mogoče raziskovalno vprašanje preučiti tudi z vidika govorjenega jezika in ugotovitve $v$ tem smislu ustrezno dopolniti.

18 Če rdečega stolpca pri določeni črki ni, to torej pomeni, da se končnica -je v vseh primerih pojavlja le sporadično.
} 


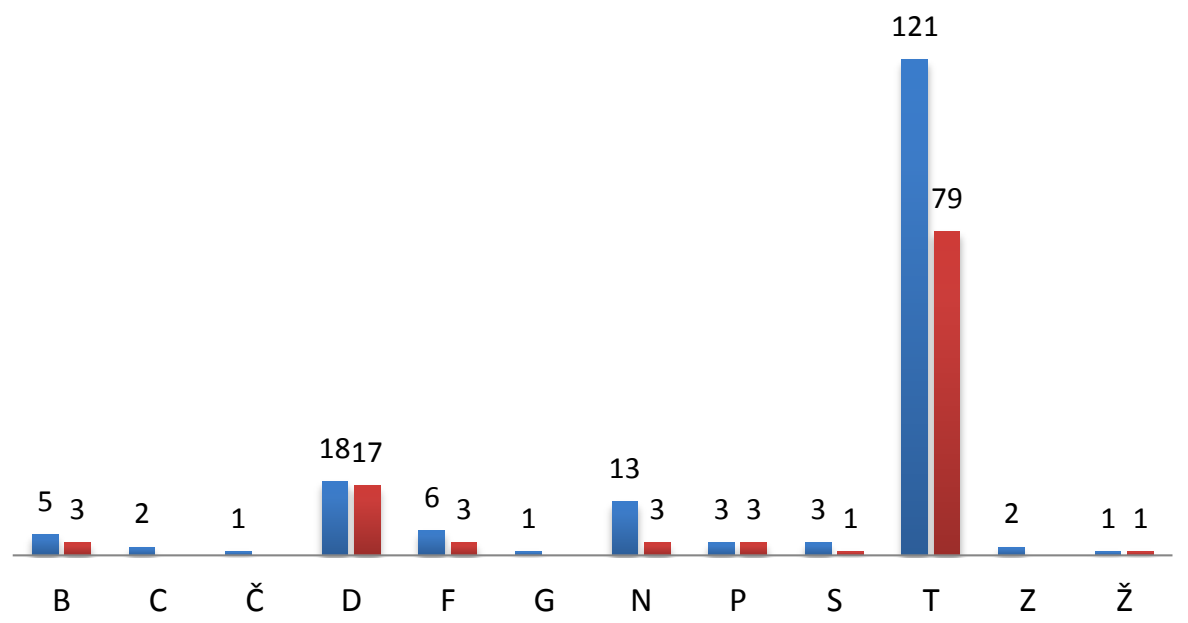

Slika 2: Število analiziranih samostalnikov glede na končno črko osnove.

Tiste skupine s Slike 2, ki izhodiščno prinašajo po vsaj pet samostalnikov, smo nadalje razvrstili glede na to, kako se konča osnovna oblika samostalnika. Tabela 4 prinaša še podatek o tem, kolikšno število samostalnikov določena skupina prinaša, in po dva ali tri primere za vsako od skupin.

\begin{tabular}{|c|c|c|l}
\hline $\begin{array}{c}\text { Osnova v } \\
\text { im. mn. }\end{array}$ & $\begin{array}{c}\text { Osnovna } \\
\text { oblika }\end{array}$ & $\begin{array}{c}\text { Št. } \\
\text { samostalnikov }\end{array}$ & Primeri \\
\hline -B & -ob & 4 & zobje, pobje, golobje \\
\hline -D & -ad & 2 & gadje, kameradje \\
\hline & -ed & 6 & sosedje, dedje, medvedje \\
\hline & -id & 2 & židje, nežidje \\
\hline -F & -od & 2 & gospodje, labodje \\
\hline$-\mathrm{N}$ & -ud & 4 & udje, judje, nejudje \\
\hline$-\mathrm{T}$ & -of & 5 & škofje, grofje, filozofje \\
\hline & -an & 13 & Osilničanje, Ložanje, Ribničanje \\
\hline & -ant & 47 & fantje, muzikantje, maturantje \\
\hline
\end{tabular}




\begin{tabular}{|l|l|l}
\hline -avt & 2 & skavtje, zmikavtje \\
\hline -ent & 22 & študentje, agentje, konkurentje \\
\hline -et & 10 & kmetje, zetje, poetje \\
\hline -it & 2 & jezuitje, banditje \\
\hline -ot & 6 & falotje, Škotje, Gotje \\
\hline -st & 5 & gostje, pustje, turistje \\
\hline -e & 5 & oče, praoče, zaspane \\
\hline
\end{tabular}

Tabela 4: Razvrstitev analiziranih samostalnikov glede na osnovno obliko.

Skupine, naštete v Tabeli 4, zajemajo 157 samostalnikov, kar pomeni 89 \% vseh identificiranih primerov. Če izvzamemo primere, pri katerih se končnica -je pojavi le sporadično, so izven Tabele 4 ostali le samostalniki: mož, las, ajd, bastard, lump, birt, pop in knap.

Korpusni podatki kažejo nekaj zanimivih tendenc. Skupina na -an denimo prinaša 13 primerov, kar je v primerjavi z ostalimi skupinami relativno veliko, vendar se varianta na -je pri vseh 13 pojavlja zelo redko. Opaziti je tudi, da je pri poimenovanjih prebivalcev (Osilničanje, Ribničanje) takšna raba močno vezana na en sam vir, to je časopis Dolenjski list. Zdi se torej, da se varianta na -je pri tej skupini umika bolj razširjeni varianti na $-i$.

Samostalniki na $-o b$, $-o f$ in različne skupine na $-d$ na drugi strani prinašajo primere, ki v rabi ohranjajo zelo visoko pogostnost variant na -je (pob, grof, gospod). Zelo majhno število samostalnikov v teh skupinah sicer nakazuje, da pogosta raba pri omenjenih primerih ne vpliva, da bi se končnica -je po analogiji uporabljala tudi pri drugih oblikovno podobnih samostalnikih, vendar je pri takšnem sklepanju potrebna previdnost. Pregled frekvenčne liste samostalnikov v korpusu Gigafida namreč pokaže, da samostalniki s temi končnimi zlogi večinoma poimenujejo nečloveško (krof, žlikrof, likof itd.), končnica -je pa je, kot rečeno, močno vezana na poimenovanje človeškega (gl. 
pogl. 3.2). K tem skupinam je mogoče uvrstiti še samostalnike na -ost in -e, ki izkazujejo primerljive tendence.

Po največ posameznih samostalnikov najdemo v skupinah na -ant, -ent, -at in -et. ${ }^{19} \mathrm{Za}$ te skupine je značilno, da imajo vsaj enega »predstavnika «, ki se v rabi zelo pogosto pojavlja s končnico -je (fantje, študentje, bratje, kmetje). Obenem pa vsebujejo vse te skupine tudi primere s sporadično rabo končnice -je, za katere lahko sklepamo, da so nastali po analogiji z v rabi pogostim primerom (fantje - maturantje). Frekvenčna lista samostalnikov v korpusu Gigafida pokaže velik nabor (tudi novejšega) besedišča, ki se konča na -ant, -ent, -at ali -et in poimenuje človeško, ugotovimo pa tudi, da pri številnih tovrstnih samostalnikih $\mathrm{v}$ korpusu raba variante na -je ni izpričana (npr. pri komandant, adjutant, vigilant). Kljub temu se zdi, da je raba končnice -je pri teh štirih skupinah pravzaprav najbolj živa, saj ne gre le za ohranjanje variante na mestih, kjer je slednja dominantna zaradi zgodovinskega razvoja, ampak se -je pojavlja tudi na novo.

Nazadnje ostanejo še skupine samostalnikov na -avt, -it in -ot, za katere je značilno, da za razliko od prejšnjih ne vsebujejo primera, pri katerem bi se končnica -je pojavljala zelo pogosto. Frekvenčna lista samostalnikov v korpusu Gigafida obenem pokaže precej primerov samostalnikov na -avt, -it in -ot, ki poimenujejo človeško, pa se končnica -je pri njih v korpusu nikoli ne pojavi (astronavt, favorit, patriot itd.). Tako kot pri skupini na -an lahko tudi pri teh skupinah zaključimo, da se raba končnice -je glede na izpričane podatke umika pogostejši izbiri -i.

\footnotetext{
19 Predvsem pri teh skupinah samostalnikov se odpira vprašanje razmerja med pojavom končnice -je in (ne)prevzetostjo posamezne besede. Pri pristopu, ki ga uporabljamo v raziskavi, besed ne ločujemo glede na to, kdaj (in od kod) so prišle v slovenski jezik, možno pa bi bilo s tega vidika podatke pogledati v ločeni raziskavi.
} 


\section{KATERO OD OBEH VARIANT UPORABITI?}

Kaj torej lahko odgovorimo jezikovnim uporabnikom, kadar jih zanima, katera od oblikovnih variant je ustreznejša/pravilnejša/varnejša izbira?

Z normativnega vidika nedvoumna je skupina samostalnikov, pri kateri je naglašena končnica -jé v standardni slovenščini edina ustrezna (lasjé, ljudjé, možjé in zobjé). Raba končnice - $i$ v standardni slovenščini pri teh primerih torej velja za napako:

- Primer 1: Ker so to prednji zobi, bi jih rada obdržala in pozdravila, če se le da. (rtvslo.si, 2010.)

Pri samostalnikih, ki izpričujejo variantnost, je dobro upoštevati predvsem podatek, kako pogosto se katera od variant pojavlja v rabi. V primerih, pri katerih je ena od končnic izrazito pogostejša kot druga, lahko predvidevamo, da bo izbira manj pogoste končnice delovala zaznamovano oz. bo v besedilu bolj opazna:

- Primer 2: Pogumni škofjeloški fanti se radi postavljajo s svojimi skoki v rečni tolmun (Dnevnik, 2000.)

- Primer 3: Stara navada je, da so na velikonočno soboto gospodinje zakurile peči ali štedilnike z blagoslovljeno žerjavico, ki so jo ponekod raznašali cerkovniki, ministrantje ali pa kar vaški otročaji. (Logaške novice, 2006.)

Kateri samostalniki izpričujejo variantnost in v kakšnem razmerju sta pri teh samostalnikih obe variantni obliki, opisujejo jezikovni priročniki, ki glede na rezultate raziskave sicer kažejo nekoliko drugačno sliko od podatkov iz sodobne jezikovne rabe (gl. pogl. 3.1). Še zlasti zanimivi se zdijo tisti primeri, ki padejo v sivo polje jezikovne (ne)pravilnosti: opis problema v Slovenski slovnici na eni strani sugerira, da raba končnice -je ni premočrtno in nepremično omejena, SP, ki vprašanje ureja z normativnega vidika, pa kot variantne beleži predvsem primere, pri katerih končnica -je prevladuje, ne pa tudi tistih, pri katerih je manj pogosto izbrana alternativa (gl. pogl. 3.1). Eden 
takih primerov je denimo samostalnik agent, pred katerim svari jezikovna uporabnica v poglavju 1.3.

Čeprav je oblika agentje redkejša od oblike agenti, se $\mathrm{v}$ rabi pojavlja nezanemarljivo pogosto in tudi razpršeno po besedilnih virih: v korpusu Gigafida najdemo 978 zadetkov z besedo agentje, oblika agenti pa je približno petkrat pogostejša. Ker varianta ni evidentirana v SSKJ in SP, jo je mogoče interpretirati kot odstop od norme, kljub temu da gre glede na podatke poglavja 3 za relativno predvidljivo in sistemsko rabo po analogiji z drugimi podobnimi primeri.

- Primer 4: Predsednikov avto je brž pospešil in tajni agentje ob njem so začeli teči. (Dnevnik, 2005.)

- Primer 5: V tistih časih je celotna zgodba o CII vsebovala nekaj romantičnega, tajni agenti so bili junaki, ki so reševali svet. (Gloss, 2004.)

Pri določenih primerih je torej normativne podatke mogoče dopolniti $\mathrm{s}$ podatki iz sodobne jezikovne rabe; kjer je raba redka, pa je to težje izvedljivo. Glede na rezultate raziskave se je $\mathrm{v}$ določeni meri mogoče opreti tudi na merilo, ali je raba končnice -je pri določenem samostalniku skladna $\mathrm{z}$ evidentiranimi trendi ali ne. Npr.: čeprav se tako oblika obročje kot akrobatje $\mathrm{v}$ korpusu pojavita $\mathrm{z}$ enim samim zadetkom, je prvi primer mogoče obravnavati drugače kot drugega. Oblika obročje je edini primer uporabe končnice -je pri samostalnikih na -č (gl. pogl. 3.3), obenem pa poimenuje nečloveško, kar za samostalnike, ki se pojavljajo s končnico -je, tipično ne velja (gl. pogl. 3.2). Na drugi strani oblika akrobatje ustreza vsem tendencam, ki jih izpričujejo analizirani korpusni podatki, je pa spričo redkosti kljub temu zaznamovana v primerjavi z obliko akrobati.

- Primer 6: Ušesa so ji krasili veliki zlati obročje. (Mlad. knjiga - leposlovje, 2001.)

- Primer 7: Nato bodo na vrsti akrobatje slovenskih aeroklubov, zgodovinska letala. (Delo, 200o.) 


\section{ZAKLJUČEK}

Nekatera vprašanja, povezana $\mathrm{z}$ obravnavano temo, ostajajo $\mathrm{v}$ prispevku neodgovorjena. Predvsem bi bilo v nadaljevanju zanimivo natančneje preučiti primere, pri katerih sta v rabi varianti približno enako pogosti (skupina $5 \mathrm{v}$ Tabeli 4). Znano je, da $\mathrm{v}$ jeziku dvojnice pogosto razvijejo razločevalne lastnosti glede pomena ali načina rabe. S primerjavo, v kakšnih kontekstih se tipično pojavlja vsaka od oblik (v kakšnih besednih zvezah, v katerih besedilnih žanrih itd.), bi lahko identificirali tovrstne tendence, če se slednje seveda pojavljajo.

Korpusna analiza, kakršno smo predstavili v tem prispevku, je dragocena, ker temelji na podatkih iz realne jezikovne rabe, s taistimi podatki pa je na drugi strani žal tudi omejena. Naloga, ki pritiče predvsem uporabnemu jezikoslovju, je najti najboljši način združitve obstoječega védenja o jeziku $\mathrm{z}$ novimi korpusnimi ugotovitvami in tako jezikovnim uporabnikom zagotoviti izčrpen ter sodoben jezikovni opis, pa tudi jezikovni predpis.

\section{LITERATURA}

Dobrovoljc, H. in Krek, S. (2011): Normativne zadrege - empirični pristop. V

S. Kranjc (ur.): Meddisciplinarnost v slovenistiki (Obdobja 30): 41-50. Ljubljana: Center za slovenščino kot drugi/tuji jezik pri Oddelku za slovenistiko Filozofske fakultete.

Gigafida, korpus slovenskih pisnih besedil: http://www.gigfida.net.

Hribar, N. (2009): Al' prav se piše ... - Spletna razglabljanja o slovenskem jeziku. V M. Stabej (ur.): Infrastruktura slovenščine in slovenistike (Obdobja 28): 171-176. Ljubljana: Znanstvena založba Filozofske fakultete.

Logar Berginc, N. in dr. (2012): Korpusi slovenskega jezika Gigafida, KRES, ccGigafida in ccKRES: gradnja, vsebina, uporaba. Ljubljana: 
Fakulteta za družbene vede, Trojina, zavod za uporabno slovenistiko.

Med.Over.Net. Dostopno prek: http://med.over.net/.

Merše, M. (2009): Oblikoslovje slovenskega knjižnega jezika 16. stoletja.

Slavistična revija (Trubarjeva številka): 47-68.

Orožen, M. (1994): Ramovševa oblikoslovno razvojna zasnova morfologije slovenskega jezika. Slavistična revija, 42 (2/3): 313-329.

Pregibnik Amebis Besana. Dostopno prek: http://besana.amebis.si/pregibanje/.

Sloleks: leksikon besednih oblik. Dostopno prek: http://www.slovenscina.eu/sloleks.

Slovar slovenskega knjižnega jezika (1970-1991/spletna različica 2000). Dostopno prek: http://bos.zrc-sazu.si/sskj.html. Ljubljana: ZRC SAZU.

Slovenski pravopis (2001). Spletna različica (2010): http://bos.zrcsazu.si/sp2001.html. Ljubljana: ZRC SAZU.

Toporišič, J. (2004): Slovenska slovnica. Maribor: Obzorja.

Žaucer, R., in Marušič, F. (2009): Jezikovno svetovanje, praksa in ideali. V M. Stabej (ur.): Infrastruktura slovenščine in slovenistike (Obdobja 28): 449-456. Ljubljana: Znanstvena založba Filozofske fakultete. 


\section{ŠTUDENTJE, ŠKRATJE AND NADŠKOFJE: ENDING -JE IN NOMINATIVE PLURAL IN NOUNS OF THE FIRST MASCULINE DECLENSION}

One of the phenomena found in conjugation and declension in the Slovene language are alternative inflectional forms. This paper focuses on one such example: certain Slovene masculine nouns in the first declension can be used in nominative plural with two different endings (e.g. študenti or študentje; in English students). While nowadays the majority of these noun forms typically end in $-i$, the ending -je remains the neutral choice for a small group of nouns.

The beginnings of the described variation go back to the 16th century when the standardisation of Slovene took place. However, from the synchronic point of view, it is not entirely clear what determines the choice between the two endings in each case. Language users, motivated to use the ending that is most "suitable" or "correct", seek guidance in language resources available to them, and sometimes supplement the available information with their own instinctbased "rules". Namely, the information that one can currently obtain from Slovene reference books contains some inconsistencies - whereas the grammatical description of the problem appears to be rather vague, the prescriptive orthographic dictionary seems to be all the more decisive.

This paper introduces new, corpus-based data related to the presented problem. It presents the findings of an analysis that is based on the Gigafida text corpus and is exploring three principal questions: (I) which nouns are used with alternative endings $-i$ and $-j e$ in contemporary written Slovene, (II) what is the distribution of these endings for each specific noun, and (III) do the identified nouns reflect any general tendencies about the usage of the endings. The paper concludes with an attempt to bridge the gap between the existing view of the described variation and the new corpus-based findings.

Keywords: Slovene morphology, alternative inflectional forms, noun, first masculine declension, ending -je 
To delo je ponujeno pod licenco Creative Commons: Priznanje avtorstvaDeljenje pod enakimi pogoji 2.5 Slovenija.

This work is licensed under the Creative Commons Attribution ShareAlike 2.5 License Slovenia.

http://creativecommons.org/licenses/by-sa/2.5/si/

(C) (1) (-) 